\title{
Cancer stem cell markers predict a poor prognosis in renal cell carcinoma: a meta-analysis
}

\author{
Bo Cheng ${ }^{1,2}$, Guosheng Yang ${ }^{2,3}$, Rui Jiang ${ }^{1}$, Yong Cheng ${ }^{1}$, Haifan Yang ${ }^{1}$, Lijun Pei ${ }^{1}$, \\ Xiaofu Qiu' ${ }^{2,3}$ \\ ${ }^{1}$ Department of Urology, The Affiliated Hospital of Southwest Medical University, Luzhou 646000, China \\ 2 Southern Medical University, Guangzhou 510280, China \\ 3 Department of Urology, Guangdong No.2 Provincial People's Hospital, Guangzhou 510317, China \\ Correspondence to: Guosheng Yang, email: 2008yangguosheng@sina.com \\ Rui Jiang, email: jiangrui@126.com
}

Keywords: renal cancer, prognosis, cancer stem cells, biomarker, meta-analysis

Received: March 31, $2016 \quad$ Accepted: August 10, 2016

Published: August 29, 2016

\section{ABSTRACT}

Background: Relevant markers of CSCs may serve as prognostic biomarkers of RCC. However, their actual prognostic significance remains inconclusive. Thus, a meta-analysis was performed to reevaluate the association of CSCs-relevant markers (CXCR4, CD133, CD44, CD105) expression with RCC prognosis more precisely.

Methods: PubMed and Embase were searched to look for eligible studies. The pooled hazard ratios (HR) with $95 \%$ confidence intervals ( $95 \% \mathrm{CI}$ ) were used to reassess the association of CSCs markers expression and RCC prognosis of overall survival (OS), cancer-specific survival (CSS), disease-free survival (DFS), and progression-free survival (PFS).

Results: There were 25 relevant articles, encompassing 2673 RCC patients, eligible for meta-analysis. Overall pooled analysis suggested that high CSCs markers expression predicted poor OS (HR, 2.10, 95\% CI: 1.73-2.55) and DFS (HR, 3.77, 95\% CI: 2.30-6.19). High CXCR4 expression predicted worse OS (HR, 2.57, 95\% CI: 1.95-3.40), CSS (HR,1.97, 95\% CI: 1.50-2.59), and DFS (HR, 5.82, 95\% CI: 3.01-11.25). CD44 over-expression correlated with a poor OS(HR,1.58, 95\% CI: 1.142.18), CSS (HR, 2.58, 95\% CI: 1.27-5.23), and DFS (HR, 4.49, 95\% CI: 2.12-9.53) in RCC patients. CD133 was an independent favorable prognostic factor for CSS (HR, $0.4,95 \%$ CI: 0.29-0.54).

Conclusions: The presence of CSCs markers correlates with poor RCC outcome. CSCs may be potentially utilized as prognostic markers to stratify RCC patients, probably representing also a novel potential therapeutic target.

\section{INTRODUCTION}

Renal cell carcinoma (RCC) is a significant health concern representing the ninth most common cancer worldwide [1]. It is estimated that there will be 62,700 new RCC cases and 14,240 deaths in the United States in 2016 [2]. Despite advances in RCC treatment and new developments in cancer surveillance, $25-30 \%$ of RCC patients present with advanced or distant metastatic disease and $20-40 \%$ develop recurrent disease after curative surgery [3,4]. Metastatic RCC is notoriously resistant to chemotherapy and radiotherapy and thus the therapeutic options are limited. Although molecularly targeted therapies have revolutionized the treatment of these patients, acquired resistance to targeted therapies eventually ensues because of secondary mutation of the target protein and molecular alterations $[5,6]$. Accordingly, the prognosis of metastatic RCC patients remains generally dismal and its 5-year survival rate is $\sim 10$ percent [1].

Prognostic biomarkers are crucial to guide therapeutic options and surveillance strategies. TNM staging, nuclear grade, and histological subtype have been the most reliable prognostic factors [7]. However, the predictive accuracy 
remains limited due to individual variations [8]. Although some new prognostic and predictive markers have been identified, only a few biomarkers are used into practice [9]. Therefore, there is a great need to identify valid therapeutic and prognostic markers for tailoring therapy and follow-up.

Cancers are believed to be driven by a small subpopulation of cancer stem cells (CSCs), which are responsible for cell self renewal, multidifferentiation, tumor relapse, and progression [10]. Multiple lines of evidence have supported the existence of CSCs in RCC $[10,11]$. RCC CSCs can be functionally identified by several cell surface markers including Prominin1(CD133), CXC chemokine receptor 4 (CXCR4), CD44, and Endoglin (CD105) [12, 13]. Studies have investigated the role of RCC CSCs markers in prognosis. One group demonstrated that CD133 expression was not associated with clinical outcomes in RCC [14]. However, another concluded that expression of CD133 predicted favorable survival [12]. RCC is characterized by dysfunctional mutation of the von Hippel Lindau (VHL) gene, inactivation of which increases expression of CXCR4 [15]. Many studies have shown that CXCR4 was overexpressed in RCC and this predicted poor prognosis [16] . Downregulation of CXCR4 could be used as promising therapeutic option. Although CD44 expression exerted an unfavorable prognosis of RCC in one study [17], other studies have not confirmed this [18, 19]. CD105 has been identified as a RCC CSCs marker but it is unclear whether or not it is prognostic [20,21].
Thus, it remains unclear which markers may be of value in determining prognosis.

Therefore, this meta-analysis was performed to determine the relationship between CSCs markers and clinical outcome of RCC. These results may provide more prognostic markers for RCC patients classification and surveillance and enable the development of CSC-targeted treatment strategies.

\section{RESULTS}

\section{Search results and study characteristics}

The PRISMA flow diagram showing study selection procedure is shown in Figure 1. Cohen's kappa for interreviewer agreement was $0.81(95 \% \mathrm{CI}=0.77$ to 0.85$)$. After the initial database searches, 386 potentially relevant publications were identified. There were 319 studies excluded by assessing the title and abstract, including 122 duplicate reports, 126 irrelevant studies, and 71 non-research articles. A total of 67 remaining articles were further full-text reviewed, and then 42 papers were excluded because of insufficient survival information or duplicated cohorts. Finally, in accordance with the inclusion criteria, 25 articles [14, 15, 17-19, 22-41] about the association of CSCs markers expression and RCC survival were eligible for the meta-analysis.

The main characteristics of the 25 eligible studies are summarized in Table 1. These studies enrolled 2673 patients and were published between 1999 and 2014 with a median

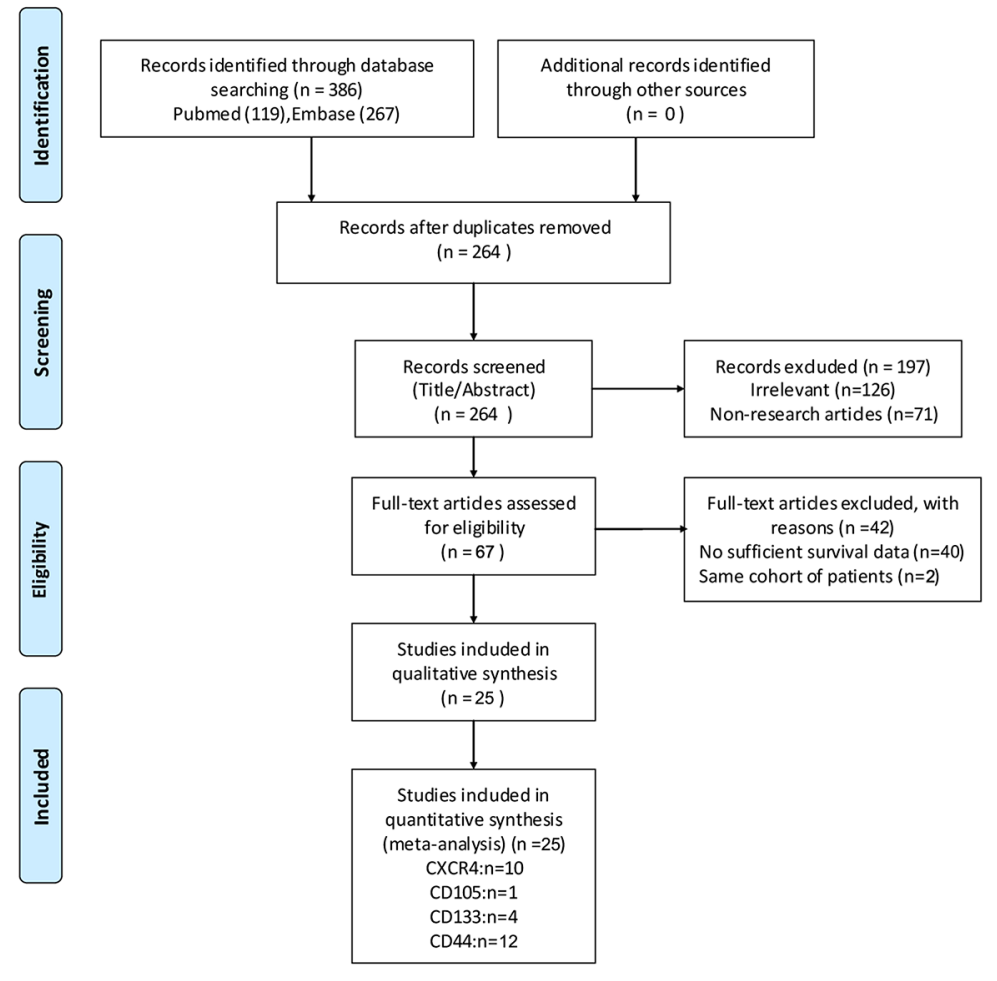

Figure 1: flow-chart of meta-analysis. 
Table 1: Baseline characteristics of studies included in the meta-analysis

\begin{tabular}{|c|c|c|c|c|c|c|c|c|c|c|c|c|}
\hline Author year & $\begin{array}{l}\text { Country } \\
\text { duration }\end{array}$ & $\begin{array}{c}\text { Markers } \\
\text { pathological } \\
\text { pattern }\end{array}$ & $\begin{array}{l}\text { Sample size } \\
\text { median age }\end{array}$ & $\begin{array}{c}\text { Treatment } \\
\text { detection } \\
\text { method }\end{array}$ & $\begin{array}{c}\text { Evaluation } \\
\text { method }\end{array}$ & $\begin{array}{c}\text { Cut-off } \\
\text { level }\end{array}$ & $\begin{array}{l}\text { Outcome } \\
\text { indexes }\end{array}$ & $\begin{array}{l}\text { Hazard } \\
\text { ratios }\end{array}$ & $95 \% \mathrm{CI}$ & $\begin{array}{c}\text { Multivariate } \\
\text { analysis }\end{array}$ & $\begin{array}{c}\text { Follow-up } \\
\text { mean/median } \\
\text { (month) }\end{array}$ & $\begin{array}{c}\text { Study } \\
\text { quality\# }\end{array}$ \\
\hline $\begin{array}{l}\text { D'Alterio } \\
\text { et al } \\
2010\end{array}$ & $\begin{array}{c}\text { Italy } \\
1999-2007\end{array}$ & $\begin{array}{c}\text { CXCR4 } \\
\text { RCC }\end{array}$ & $\begin{array}{c}240 \\
61(26-84)\end{array}$ & $\begin{array}{l}\text { SR } \\
\text { IHC }\end{array}$ & Percentage & $>20 \%$ & DFS & 3.40 & $1.11-10.38$ & Yes & 64 & 7 \\
\hline $\begin{array}{l}\text { Huang et al } \\
2014\end{array}$ & $\begin{array}{l}\text { China } \\
\text { NR }\end{array}$ & $\begin{array}{c}\text { CXCR4 } \\
\text { RCC }\end{array}$ & $\begin{array}{c}45 \\
57.7(21-84)\end{array}$ & $\begin{array}{c}\text { NR } \\
\text { TMA-IHC }\end{array}$ & $\mathrm{CS}$ & NR & DFS & 5.62 & $\begin{array}{c}1.02- \\
30.96^{*} \\
1.21- \\
39.23^{*}\end{array}$ & No & NR & 5 \\
\hline $\begin{array}{l}\text { Li et al } \\
2011\end{array}$ & $\begin{array}{c}\text { China } \\
\text { 2001-2005 }\end{array}$ & $\begin{array}{l}\text { CXCR4 } \\
\text { LARCC }\end{array}$ & $\begin{array}{c}117 \\
57.7(31-82)\end{array}$ & $\begin{array}{l}\text { SR } \\
\mathrm{IHC}\end{array}$ & Intensity & NR & OS & 4.12 & $1.79-9.47$ & Yes & 51 & 8 \\
\hline $\begin{array}{l}\text { D'Alterio } \\
\text { et al } \\
2012\end{array}$ & $\begin{array}{c}\text { Italy } \\
2005-2009\end{array}$ & $\begin{array}{l}\text { CXCR4 } \\
\text { mRCC }\end{array}$ & $\begin{array}{l}62 \\
55\end{array}$ & $\begin{array}{l}\text { Sunitinib } \\
\text { IHC }\end{array}$ & Percentage & $>20 \%$ & $\begin{array}{l}\text { PFS } \\
\text { OS }\end{array}$ & $\begin{array}{l}2.04 \\
1.48\end{array}$ & $\begin{array}{l}1.08-3.84 \\
0.93-2.38\end{array}$ & Yes & 29 & 6 \\
\hline $\begin{array}{l}\text { Li et al } \\
2013\end{array}$ & $\begin{array}{c}\text { France } \\
1999-2005\end{array}$ & $\begin{array}{l}\text { CXCR4 } \\
\text { ccRCC }\end{array}$ & $\begin{array}{c}104 \\
64.5(34-86)\end{array}$ & $\begin{array}{c}\text { SR } \\
\text { IHC }\end{array}$ & Percentage & $>85 \%$ & $\begin{array}{l}\text { CSS } \\
\text { OS }\end{array}$ & $\begin{array}{l}2.60 \\
2.20\end{array}$ & $\begin{array}{l}1.11-6.10 \\
1.11-4.38\end{array}$ & Yes & 79.5 & 7 \\
\hline $\begin{array}{l}\text { Wang et al } \\
2012\end{array}$ & $\begin{array}{c}\text { China } \\
\text { 2002-2003 }\end{array}$ & $\begin{array}{c}\text { CXCR4 } \\
\text { RCC }\end{array}$ & $\begin{array}{c}97 \\
55.4(21-81)\end{array}$ & $\begin{array}{c}\text { SR } \\
\text { TMA-IHC }\end{array}$ & Percentage & $\geq 30 \%$ & $\begin{array}{l}\text { DFS } \\
\text { OS }\end{array}$ & $\begin{array}{l}8.03 \\
6.95\end{array}$ & $\begin{array}{l}3.19-20.22 \\
2.50-19.31\end{array}$ & Yes & NA & 7 \\
\hline $\begin{array}{l}\text { Chen et al } \\
2014\end{array}$ & $\begin{array}{l}\text { Germany } \\
1992-2011\end{array}$ & $\begin{array}{c}\text { CXCR4 } \\
\mathrm{ccRCC} / \\
\mathrm{mRCC}\end{array}$ & $\begin{array}{c}44 \\
\mathrm{NR}\end{array}$ & $\begin{array}{c}\text { SR } \\
\text { RT-PCR }\end{array}$ & NR & NR & CSS & 3.8 & $1.1-13.9$ & No & NA & 5 \\
\hline $\begin{array}{l}\text { Staller et al } \\
2003\end{array}$ & $\begin{array}{c}\text { Switzerland } \\
\text { NR }\end{array}$ & $\begin{array}{l}\text { CXCR4 } \\
\text { ccRCC }\end{array}$ & $\begin{array}{l}195 \\
\text { NR }\end{array}$ & $\begin{array}{c}\text { NR } \\
\text { TMA-IHC }\end{array}$ & NR & NR & CSS & 1.84 & $1.37-2.47^{*}$ & No & NA & 5 \\
\hline $\begin{array}{l}\text { An et al } \\
\text { (cohort 1) } \\
2014\end{array}$ & $\begin{array}{c}\text { China } \\
\text { 1996-2006 }\end{array}$ & $\begin{array}{l}\text { CXCR4 } \\
\text { ccRCC }\end{array}$ & $\begin{array}{c}125 \\
57.6\end{array}$ & $\begin{array}{c}\text { SR } \\
\text { TMA-IHC }\end{array}$ & $\mathrm{CS}$ & $>2$ & os & 3.38 & $1.49-7.68$ & Yes & $62(7-116)$ & 9 \\
\hline $\begin{array}{l}\text { An et al } \\
\text { (cohort 2) } \\
2014\end{array}$ & $\begin{array}{c}\text { China } \\
\text { 1996-2006 }\end{array}$ & $\begin{array}{l}\text { CXCR4 } \\
\text { ccRCC }\end{array}$ & $\begin{array}{l}100 \\
60.5\end{array}$ & $\begin{array}{c}\text { SR } \\
\text { TMA-IHC }\end{array}$ & $\mathrm{CS}$ & $>2$ & OS & 2.88 & $1.26-6.59$ & Yes & $68(8-117)$ & 9 \\
\hline $\begin{array}{l}\text { Gassenmaier } \\
\text { et al } \\
2012\end{array}$ & $\begin{array}{l}\text { Germany } \\
\text { NR }\end{array}$ & $\begin{array}{c}\text { CXCR4 } \\
\mathrm{RCC} / \mathrm{mRCC}\end{array}$ & $\begin{array}{c}88 \\
\text { NR }\end{array}$ & $\begin{array}{l}\mathrm{NC} \\
\mathrm{IHC}\end{array}$ & NR & NR & OS & 4.1 & $1.2-14.8$ & Yes & NA & 6 \\
\hline $\begin{array}{l}\text { Saroufim } \\
\text { et al } \\
2014\end{array}$ & $\begin{array}{c}\text { France } \\
\text { 2006-2009 }\end{array}$ & $\begin{array}{l}\mathrm{CD} 105 \\
\text { ccRCC }\end{array}$ & $\begin{array}{c}102 \\
62.2(22-84)\end{array}$ & $\begin{array}{c}\text { SR } \\
\text { IHC }\end{array}$ & Intensity & NR & $\begin{array}{l}\text { OS } \\
\text { DFS }\end{array}$ & $\begin{array}{l}3.76 \\
2.82\end{array}$ & $\begin{array}{l}1.63-8.66 \\
0.99-8.05\end{array}$ & Yes & $52(4-90)$ & 8 \\
\hline $\begin{array}{l}\text { Zhang et al } \\
2013\end{array}$ & $\begin{array}{c}\text { China } \\
\text { 1984-2008 }\end{array}$ & $\begin{array}{l}\mathrm{CD} 133 \\
\mathrm{mRCC}\end{array}$ & $\begin{array}{c}110 \\
58(36-76)\end{array}$ & $\begin{array}{c}\text { SR } \\
\text { IHC }\end{array}$ & NR & NR & OS & 1.59 & $0.84-2.99$ & Yes & 64.71 & 8 \\
\hline $\begin{array}{l}\text { Kim et al } \\
2012\end{array}$ & $\begin{array}{c}\text { South Korea } \\
1996-2008\end{array}$ & $\begin{array}{l}\text { CD133 } \\
\text { pRCC }\end{array}$ & $\begin{array}{c}119 \\
53(11-75)\end{array}$ & $\begin{array}{c}\text { SR } \\
\text { TMA-IHC }\end{array}$ & Percentage & NR & CSS & 0.03 & $0.00-9.54$ & No & $47.3(0.6-157.7)$ & 7 \\
\hline $\begin{array}{l}\text { Costa et al } \\
2011\end{array}$ & $\begin{array}{c}\text { Brazil } \\
1992-2009\end{array}$ & $\begin{array}{l}\text { CD133 } \\
\text { RCC }\end{array}$ & $\begin{array}{c}142 \\
54.7(23-81)\end{array}$ & $\begin{array}{c}\text { SR } \\
\text { TMA-IHC }\end{array}$ & $\mathrm{CS}$ & NR & CSS & 0.40 & $0.29-0.54^{*}$ & Yes & NR & 6 \\
\hline $\begin{array}{l}\text { D'Alterio } \\
\text { et al } \\
2010\end{array}$ & $\begin{array}{c}\text { Italy } \\
1999-2007\end{array}$ & $\begin{array}{l}\mathrm{CD} 133 \\
\mathrm{RCC}\end{array}$ & $\begin{array}{c}240 \\
61(26-84)\end{array}$ & $\begin{array}{c}\text { SR } \\
\text { IHC }\end{array}$ & Percentage & $>5 \%$ & DFS & 1.26 & $0.55-2.87$ & Yes & 64 & 7 \\
\hline $\begin{array}{l}\text { Mikami et al } \\
2014\end{array}$ & $\begin{array}{c}\text { Japan } \\
1991-2003\end{array}$ & $\begin{array}{c}\mathrm{CD} 44 \\
\mathrm{ccRCC} / \\
\mathrm{mRCC}\end{array}$ & $\begin{array}{l}120 \\
\text { NR }\end{array}$ & $\begin{array}{c}\text { SR } \\
\text { IHC }\end{array}$ & Percentage & NR & OS & 1.53 & $0.37-6.34$ & Yes & NR & 8 \\
\hline $\begin{array}{l}\text { Qin et al } \\
2014\end{array}$ & $\begin{array}{c}\text { China } \\
\text { 2006-2012 }\end{array}$ & $\begin{array}{l}\text { CD44 } \\
\text { ccRCC }\end{array}$ & $\begin{array}{c}75 \\
58.7(29-82)\end{array}$ & $\begin{array}{c}\text { SR } \\
\text { TMA-IHC }\end{array}$ & $\mathrm{CS}$ & NR & Os & 2.67 & $0.83-8.61$ & No & $52.6(2-74)$ & 9 \\
\hline $\begin{array}{l}\text { Zhang et al } \\
2013\end{array}$ & $\begin{array}{c}\text { China } \\
\text { 1984-2008 }\end{array}$ & $\begin{array}{l}\mathrm{CD} 44 \\
\mathrm{mRCC}\end{array}$ & $\begin{array}{c}110 \\
58(36-76)\end{array}$ & $\begin{array}{c}\text { SR } \\
\text { IHC }\end{array}$ & NR & NR & Os & 1.46 & $0.82-2.62$ & Yes & 64.71 & 8 \\
\hline $\begin{array}{l}\text { Costa et al } \\
2012\end{array}$ & $\begin{array}{c}\text { Brazil } \\
1992-2009\end{array}$ & $\begin{array}{c}\mathrm{CD} 44 \\
\mathrm{RCC} / \mathrm{mRCC}\end{array}$ & $\begin{array}{c}99 \\
55.5(27-79)\end{array}$ & $\begin{array}{c}\text { SR } \\
\text { TMA-IHC }\end{array}$ & $\mathrm{CS}$ & NR & CSS & 1.11 & $0.39-3.18$ & Yes & NR & 6 \\
\hline $\begin{array}{l}\text { Tawfik et al } \\
2007\end{array}$ & $\begin{array}{c}\text { USA } \\
1995-2004\end{array}$ & $\begin{array}{c}\mathrm{CD} 44 \\
\mathrm{RCC} / \mathrm{mRCC}\end{array}$ & $\begin{array}{c}62 \\
61(36-81)\end{array}$ & $\begin{array}{c}\text { SR } \\
\text { IHC }\end{array}$ & CS & NR & OS & 1.21 & $0.61-2.40^{*}$ & Yes & $22(0.1-108)$ & 5 \\
\hline $\begin{array}{l}\text { Lucin et al } \\
2004\end{array}$ & $\begin{array}{c}\text { Croatia } \\
1990-1998\end{array}$ & $\begin{array}{c}\mathrm{CD} 44 \\
\mathrm{RCC} / \mathrm{mRCC}\end{array}$ & $\begin{array}{l}116 \\
\text { NR }\end{array}$ & $\begin{array}{l}\mathrm{NR} \\
\mathrm{IHC}\end{array}$ & Percentage & $>25 \%$ & OS & 3.25 & $0.93-11.35$ & Yes & $85(1-165)$ & 7 \\
\hline $\begin{array}{l}\text { Yildiz et al } \\
2004\end{array}$ & $\begin{array}{c}\text { Turkey } \\
\text { 1988-1997 }\end{array}$ & $\begin{array}{l}\mathrm{CD} 44 \\
\mathrm{RCC}\end{array}$ & $\begin{array}{c}48 \\
54(20-82)\end{array}$ & $\begin{array}{c}\text { SR } \\
\text { IHC }\end{array}$ & Percentage & NR & CSS & 3.67 & $\begin{array}{c}0.89- \\
15.13^{*}\end{array}$ & No & $48(1-168)$ & 7 \\
\hline
\end{tabular}

(Continued) 


\begin{tabular}{|c|c|c|c|c|c|c|c|c|c|c|c|c|}
\hline Author year & $\begin{array}{l}\text { Country } \\
\text { duration }\end{array}$ & $\begin{array}{c}\text { Markers } \\
\text { pathological } \\
\text { pattern }\end{array}$ & $\begin{array}{l}\text { Sample size } \\
\text { median age }\end{array}$ & $\begin{array}{c}\text { Treatment } \\
\text { detection } \\
\text { method }\end{array}$ & $\begin{array}{l}\text { Evaluation } \\
\text { method }\end{array}$ & $\begin{array}{c}\text { Cut-off } \\
\text { level }\end{array}$ & $\begin{array}{c}\text { Outcome } \\
\text { indexes }\end{array}$ & $\begin{array}{c}\text { Hazard } \\
\text { ratios }\end{array}$ & $95 \% \mathrm{CI}$ & $\begin{array}{c}\text { Multivariate } \\
\text { analysis }\end{array}$ & $\begin{array}{c}\text { Follow-up } \\
\text { mean/median } \\
\text { (month) }\end{array}$ & $\begin{array}{c}\text { Study } \\
\text { quality\# }\end{array}$ \\
\hline $\begin{array}{l}\text { Bamias et al } \\
2003\end{array}$ & $\begin{array}{c}\text { Greece } \\
1996-1998\end{array}$ & $\begin{array}{l}\text { CD44 } \\
\text { RCC }\end{array}$ & $\begin{array}{c}92 \\
64(46-86)\end{array}$ & $\begin{array}{c}\text { SR } \\
\text { IHC }\end{array}$ & Percentage & $>10 \%$ & OS & 0.91 & $0.42-1.97^{*}$ & No & $41.5(30-65)$ & 5 \\
\hline $\begin{array}{l}\text { Rioux- } \\
\text { Leclercq } \\
\text { et al } \\
2001\end{array}$ & $\begin{array}{c}\text { France } \\
1992-1993\end{array}$ & $\begin{array}{l}\mathrm{CD} 44 \\
\mathrm{RCC}\end{array}$ & $\begin{array}{c}73 \\
64(37-86)\end{array}$ & $\begin{array}{l}\mathrm{NR} \\
\mathrm{IHC}\end{array}$ & Percentage & NR & CSS & 2.19 & $1.21-3.96^{*}$ & Yes & $52(9-75)$ & 7 \\
\hline $\begin{array}{l}\text { Daniel et al } \\
2001\end{array}$ & $\begin{array}{c}\text { France } \\
1987-1993\end{array}$ & $\begin{array}{l}\mathrm{CD} 44 \\
\text { ccRCC }\end{array}$ & $\begin{array}{c}97 \\
62.9(37-85)\end{array}$ & $\begin{array}{c}\text { SR } \\
\text { IHC }\end{array}$ & Percentage & NR & DFS & 4.7 & $1.1-20.8$ & Yes & $58.1(1-111)$ & 8 \\
\hline $\begin{array}{l}\text { Paradis et al } \\
1999\end{array}$ & $\begin{array}{c}\text { France } \\
1981-1990\end{array}$ & $\begin{array}{l}\text { CD44 } \\
\text { ccRCC }\end{array}$ & $\begin{array}{c}91 \\
58(29-81)\end{array}$ & $\begin{array}{c}\text { SR } \\
\text { IHC }\end{array}$ & Intensity & NR & DFS & 2.89 & $1.5-5.2$ & Yes & $54(1-38)$ & 7 \\
\hline \multirow[t]{2}{*}{$\begin{array}{l}\text { Jeong et al } \\
2012\end{array}$} & \multirow[t]{2}{*}{$\begin{array}{l}\text { South Korea } \\
2000-2006\end{array}$} & \multirow[t]{2}{*}{$\begin{array}{l}\text { CD44 } \\
\text { ccRCC }\end{array}$} & \multirow[t]{2}{*}{$\begin{array}{c}110 \\
60(30-78)\end{array}$} & \multirow[t]{2}{*}{$\begin{array}{c}\text { SR } \\
\text { TMA-IHC }\end{array}$} & \multirow[t]{2}{*}{ Intensity } & \multirow[t]{2}{*}{$>2$} & CSS & 7.93 & $2.11-29.74$ & \multirow[t]{2}{*}{ Yes } & \multirow[t]{2}{*}{ NR } & \multirow[t]{2}{*}{6} \\
\hline & & & & & & & OS & 4.00 & $1.44-11.12$ & & & \\
\hline
\end{tabular}

Notes: HR: Hazard ratio; OS: Overall survival; DFS: Disease free survival; PFS: Progression free survival; CSS: Cancer specific survival NR: Not reported; SR: Surgical Resection(radical nephrectomy or partial nephrectomy); IHC: Immunohistochemistry; CS: Complex score combining intensity and percentage; \# Study quality was judged based on the Newcastle-Ottawa Scale (range, 1-9); *Estimated by survival curves. RCC: Renal cell carcinoma; ccRCC: Clear-cell renal cell carcinoma; mRCC: Metastatic renal cell carcinoma; LARCC: Locally advanced renal cell carcinoma; pRCC: Papillary renal cell carcinoma.

follow up of 54 months (range 22-85 months). All studies were retrospective cohort designs and the range of median age was 53- 64.5 years. Geographically, 10 studies were conducted in Asia, 12 in Europe, 1 in North America, and 2 in South America. There were 18 articles which reported HR and 95\% CI directly, and the remaining studies were extrapolated and calculated from Kaplan-Meier curves. There were 21 studies which had their survival outcomes adjust for covariates (Supplemental Table S1). The CSCs markers expression was divided into positive and negative groups in all eligible studies. CSCs markers varied from different articles: 10 studies about CXCR4 expression $[14,15,22-24,26,27,30,36,41], 1$ study about CD105 expression [35], 4 studies about CD133 expression [14, 29, $38,40]]$, and 12 studies about CD44 expression [17-19, 25, 28, 31-34, 37-39]. According to NOS quality assessment, 14 studies were categorized as of high quality.

\section{CSCs markers expression and OS}

A total of 1525 RCC patients from 16 studies included data for OS [17-19, 22, 24, 26-28, 30, 31, 33, 35, 36, 38, 41]. As shown in Figure 2, CSCs markers over-expression was significantly associated with poorer OS (pooled HR = $2.10,95 \% \mathrm{CI}=1.73-2.55, \mathrm{P}<0.00001)$. The pooled data were not substantially heterogeneous $\left(I^{2}=42 \%\right)$; thus, a fixed-effect model was used. We investigated the association of individual CSCs markers with OS. High expression of CXCR4 (pooled HR $=2.57,95 \% \mathrm{CI}=1.95-3.40, \mathrm{P}<$ 0.00001 ) and CD44 (pooled HR $=1.58,95 \% \mathrm{CI}=1.14-2.18$, $\mathrm{P}=0.005$ ) predicted worse OS. Limited articles reported the association of CD133 and CD105 with OS. One study [38] reported CD133 was not found to be a prognostic factor for OS using multivariate analysis $(\mathrm{HR}=1.59,95 \% \mathrm{CI}=$ $0.84-2.99, \mathrm{P}=0.15)$. Another study found that tumoral CD105 predicted poor $\mathrm{OS}(\mathrm{HR}=3.76,95 \% \mathrm{CI}=1.63-8.67$, $\mathrm{P}=0.002$ ). Exploratory subgroup analyses were conducted according to study geography, sample size, study quality, disease stage, and HR origin. As shown in Table 2 , these variables did not alter the prognostic role of CXCR4 in OS. Interestingly, the prognostic impact of CXCR4 was numerically higher in the Asia group (pooled HR $=3.97$, $95 \% \mathrm{CI}=2.61-6.04, \mathrm{P}<0.00001)$ and high-quality studies group (pooled $\mathrm{HR}=3.30,95 \% \mathrm{CI}=2.29-4.76, \mathrm{P}<0.00001$ ). Patients with CD44 high expression showed worse OS with respect to Asia (pooled $\mathrm{HR}=1.97,95 \% \mathrm{CI}=1.23-3.16, \mathrm{P}$ $=0.005$ ), large sample size (pooled $\mathrm{HR}=2.07,95 \% \mathrm{CI}=$ 1.23-3.48, $\mathrm{P}=0.006)$, and $\mathrm{HR}$ reported from study subgroup (pooled $\mathrm{HR}=2.04,95 \% \mathrm{CI}=1.35-3.08, \mathrm{P}=0.0008$ ).

\section{CSCs markers expression and CSS}

Nine studies comprising 934 patients reported the association of CSCs markers expression with $\operatorname{CSS}[15$, 23, 28, 29, 34, 37, 39-41] . As shown in Figure 3, overall analysis suggested that high expression of CSCs markers was not linked to $\mathrm{CSS}$ (pooled $\mathrm{HR}=1.87,95 \% \mathrm{CI}=0.90$ $3.89, \mathrm{P}=0.09$ ). Furthermore, high CXCR4 expression was significantly related to poor CSS (pooled HR $=1.97,95 \%$ $\mathrm{CI}=1.50-2.59, \mathrm{P}<0.00001)$. RCC patients possessing high CD133 expression improved CSS (pooled $\mathrm{HR}=0.4,95 \% \mathrm{CI}$ $=0.29-0.54, \mathrm{P}<0.00001)$. There was a significant association between enhanced CD44 expression and CSS (pooled HR = $2.58,95 \% \mathrm{CI}=1.27-5.23, \mathrm{P}=0.009)$. Subgroup analyses were carried out to explore heterogeneity. As shown in Table 2, results revealed that CD44 expression was not associated with CSS in low-quality studies group (pooled $\mathrm{HR}=2.85$, $95 \% \mathrm{CI}=0.42-19.47, \mathrm{P}=0.29, \mathrm{I}^{2}=81 \%$ ).

\section{CSCs markers expression and DFS}

Eight studies encompassing 1022 patients assessed the relationship between CSCs markers expression and DFS $[14,25,27,28,32,35,36]$. As seen in Figure 4, 
overall, the adverse prognosis effect of high CSCs markers expression on DFS was seen (pooled $\mathrm{HR}=3.77,95 \% \mathrm{CI}$ $=2.30-6.19, \mathrm{P}<0.00001)$. A combined analysis showed that high CXCR4 expression (pooled $\mathrm{HR}=5.82,95 \% \mathrm{CI}$ $=3.01-11.25, \mathrm{P}<0.0001$ ) and CD44 expression (pooled $\mathrm{HR}=4.49,95 \% \mathrm{CI}=2.12-9.53, \mathrm{P}<0.0001)$ predicted poor DFS. One study showed [35] no significant effect of CD105 in DFS $(\mathrm{HR}=2.82,95 \% \mathrm{CI}=0.99-9.06, \mathrm{P}=0.05)$. High CD133 expression did not correlate with DFS (HR $=1.26,95 \% \mathrm{CI}=0.55-2.87, \mathrm{P}=0.58)$ in 1 study [14]. We did not perform a subgroup for the association between individual CSCs markers and DFS because the eligible studies were limited. Only one article [24] reported PFS for metastatic RCC patients. The study showed that high CXCR4 expression predicted sunitinib responsiveness on $\mathrm{PFS}(\mathrm{HR}=1.26,95 \% \mathrm{CI}=0.55-2.87, \mathrm{P}=0.04)$.

\section{Sensitivity analysis}

In order to gauge the stability of the results, sensitivity analysis was performed by assessing the potential impact of individual studies on pooled data. As shown in Table 3 , the combined HR of the association of CD44 expression with CSS was affected and heterogeneity was observed again by omitting 1 study [34]. However, the remaining pooled HR was not significantly altered.

\section{Publication bias}

Publication bias analysis of the studies was performed to test the reliability of the results. As shown in Figure 5, the funnel plots showed evidence for symmetry in CSS and
DFS, but not in OS studies, suggesting that a publication bias about OS possibly existed. Then, Begg's and Egger's tests were conducted to more precisely assess the bias. As shown in Table 4 , especially studies concerning CXCR4 expression and OS showed publication bias as analyzed by Egger's test $(\mathrm{t}$-value $=3.95,95 \% \mathrm{CI}=1.17-4.97, \mathrm{P}=0.01)$ and Begg's test $(\mathrm{P}=0.03)$.

\section{DISCUSSION}

Although treatments for RCC have recently developed rapidly, including introduction of tyrosine kinase inhibitors (TKIs) and mTOR kinase inhibitors $[42,43]$, complete responses are rare. Thus, RCC still remains one of the deadliest forms of cancer and has a poor clinical outcome with recurrence or incomplete resection. RCC is characterized by a wide variation in prognosis. Biomolecular markers offer potential for additional information in cancer prognostic and predictive values. The conventional prognostic variables such as staging or grading cannot well predict clinical outcome on an individual basis [18]. From a clinical perspective, identifying new biomarkers for prognosis to guide surveillance is important and urgent.

Accumulated evidence shows that cancer can be considered as a stem cell disease [44] . CSCs, which comprise a small subpopulation of cancer cells, exhibit self-renewal ability and cancer-propagating capacity $[45,46]$. The concept of contribution of CSCs to cancer initiation and therapeutic resistance is widely accepted, so a better understanding of the characteristics of CSCs

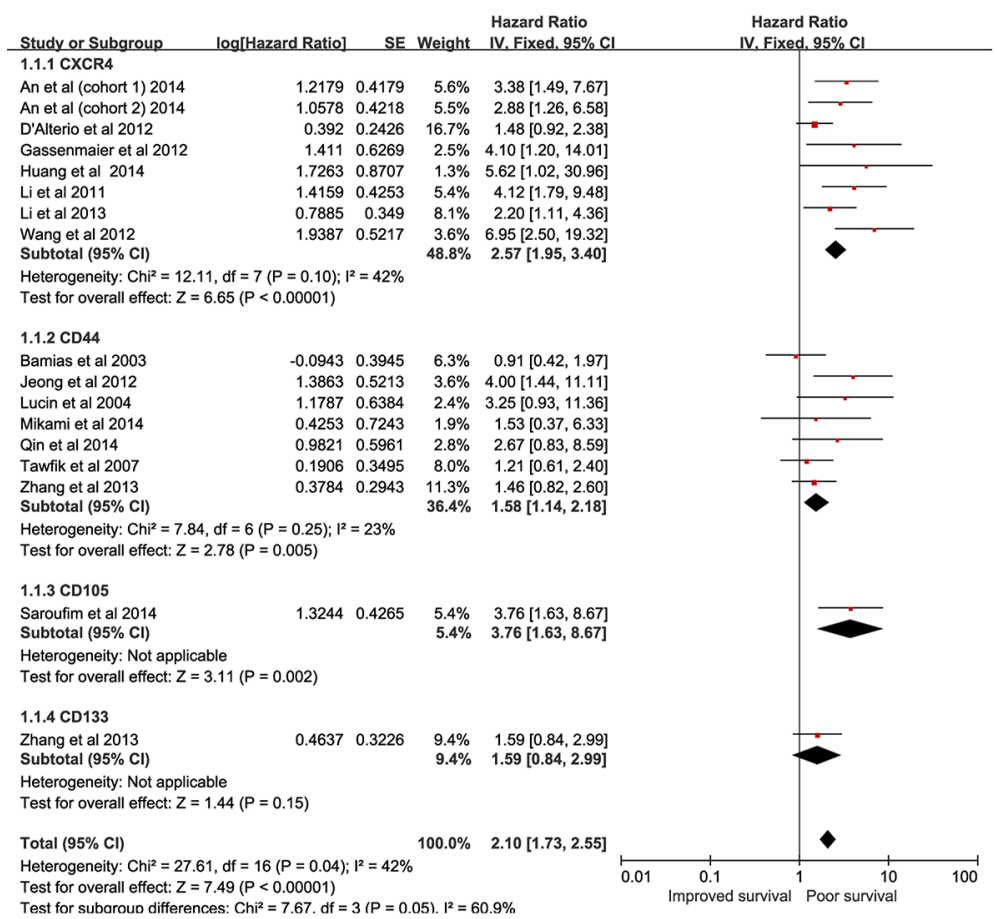

Figure 2: forest plot reflects HR with $95 \%$ CI for OS. 
Table 2: Subgroup analyses for OS and CSS

\begin{tabular}{|c|c|c|c|c|c|c|c|c|c|c|}
\hline \multirow[t]{2}{*}{ Outcomes } & \multirow[t]{2}{*}{ Subgroup } & \multirow{2}{*}{$\begin{array}{l}\text { No. Of } \\
\text { studies }\end{array}$} & \multirow{2}{*}{$\begin{array}{c}\text { No. Of } \\
\text { patients }\end{array}$} & \multirow[t]{2}{*}{ HR } & \multicolumn{2}{|c|}{$95 \%$ CI } & \multicolumn{2}{|c|}{ Effect Size } & \multicolumn{2}{|c|}{ Heterogeneity } \\
\hline & & & & & & & $\mathbf{Z}$ & P-value & P-value & $I^{2}$ \\
\hline \multirow[t]{15}{*}{ OS(CXCR4) } & Geography & & & & & & & & & \\
\hline & Asia & 5 & 484 & 3.97 & 2.61 & 6.04 & 6.45 & $<0.00001$ & 0.73 & $0 \%$ \\
\hline & Europe & 3 & 254 & 1.83 & 1.26 & 2.65 & 3.17 & 0.001 & 0.26 & $26 \%$ \\
\hline & Sample size & & & & & & & & & \\
\hline & Small $(\mathrm{n}<100)$ & 4 & 292 & 2.23 & 1.50 & 3.31 & 3.97 & $<0.00001$ & 0.02 & $69 \%$ \\
\hline & Large $(n>100)$ & 4 & 446 & 2.96 & 2.00 & 4.38 & 5.43 & $<0.00001$ & 0.70 & $0 \%$ \\
\hline & Study quality & & & & & & & & & \\
\hline & Low-quality & 3 & 195 & 1.82 & 1.19 & 2.80 & 2.74 & 0.006 & 0.13 & $51 \%$ \\
\hline & High-quality & 5 & 543 & 3.30 & 2.29 & 4.76 & 6.40 & $<0.00001$ & 0.44 & $0 \%$ \\
\hline & Disease stage & & & & & & & & & \\
\hline & Non-metastatic & 5 & 471 & 2.32 & 2.18 & 4.80 & 5.81 & $<0.00001$ & 0.43 & $0 \%$ \\
\hline & Metastatic/mixed & 3 & 267 & 2.06 & 1.39 & 3.40 & 3.61 & 0.0003 & 0.06 & $65 \%$ \\
\hline & HR & & & & & & & & & \\
\hline & Reported in study & 7 & 693 & 2.52 & 1.90 & 3.34 & 6.42 & $<0.00001$ & 0.08 & $47 \%$ \\
\hline & $\begin{array}{l}\text { Estimated from } \\
\text { survival curves }\end{array}$ & 1 & 45 & 5.62 & 1.02 & 30.96 & 1.98 & 0.05 & - & - \\
\hline \multirow[t]{15}{*}{ OS(CD44) } & Geography & & & & & & & & & \\
\hline & Asia & 4 & 415 & 1.97 & 1.23 & 3.16 & 2.81 & 0.005 & 0.35 & $8 \%$ \\
\hline & Non-Asia & 3 & 270 & 1.30 & 0.72 & 2.36 & 0.88 & 0.38 & 0.23 & $31 \%$ \\
\hline & Sample size & & & & & & & & & \\
\hline & Small $(\mathrm{n}<100)$ & 3 & 229 & 1.25 & 0.75 & 2.08 & 0.87 & 0.39 & 0.32 & $12 \%$ \\
\hline & Large $(\mathrm{n}>100)$ & 4 & 456 & 2.07 & 1.23 & 3.48 & 2.73 & 0.006 & 0.31 & $17 \%$ \\
\hline & Study quality & & & & & & & & & \\
\hline & Low-quality & 3 & 264 & 1.53 & 0.70 & 3.31 & 1.07 & 0.29 & 0.07 & $63 \%$ \\
\hline & High-quality & 4 & 421 & 1.78 & 1.13 & 2.81 & 2.50 & 0.01 & 0.6 & $0 \%$ \\
\hline & Disease stage & & & & & & & & & \\
\hline & Non-metastatic & 4 & 387 & 1.75 & 0.96 & 3.18 & 1.84 & 0.07 & 0.11 & $50 \%$ \\
\hline & Metastatic/mixed & 3 & 298 & 1.52 & 0.87 & 2.65 & 1.49 & 0.14 & 0.4 & $0 \%$ \\
\hline & HR & & & & & & & & & \\
\hline & Reported in study & 5 & 531 & 2.04 & 1.35 & 3.08 & 3.37 & 0.0008 & 0.43 & $0 \%$ \\
\hline & $\begin{array}{l}\text { Estimated from } \\
\text { survival curves }\end{array}$ & 2 & 154 & 1.07 & 0.64 & 1.78 & 0.25 & 0.8 & 0.59 & $0 \%$ \\
\hline \multirow[t]{9}{*}{ CSS(CD44) } & Geography & & & & & & & & & \\
\hline & Asia & 1 & 110 & 7.93 & 2.11 & 27.95 & 3.07 & 0.002 & - & - \\
\hline & Europe & 2 & 121 & 2.37 & 1.37 & 4.09 & 3.08 & 0.002 & 0.51 & $0 \%$ \\
\hline & South America & 1 & 99 & 1.11 & 0.39 & 3.18 & 0.20 & 0.84 & - & - \\
\hline & Sample size & & & & & & & & & \\
\hline & Small $(\mathrm{n}<100)$ & 3 & 220 & 2.01 & 1.24 & 3.27 & 2.83 & 0.005 & 0.37 & $0 \%$ \\
\hline & Large $(n>100)$ & 1 & 110 & 7.93 & 2.11 & 27.95 & 3.07 & 0.002 & - & - \\
\hline & Study quality & & & & & & & & & \\
\hline & Low-quality & 2 & 209 & 2.85 & 0.42 & 19.47 & 1.07 & 0.29 & 0.02 & $\begin{array}{l}81 \% \\
\text { Itinued) }\end{array}$ \\
\hline
\end{tabular}




\begin{tabular}{|c|c|c|c|c|c|c|c|c|c|c|}
\hline \multirow[t]{2}{*}{ Outcomes } & \multirow[t]{2}{*}{ Subgroup } & \multirow{2}{*}{$\begin{array}{l}\text { No. Of } \\
\text { studies }\end{array}$} & \multirow{2}{*}{$\begin{array}{c}\text { No. Of } \\
\text { patients }\end{array}$} & \multirow[t]{2}{*}{ HR } & \multicolumn{2}{|c|}{$95 \% \mathrm{CI}$} & \multicolumn{2}{|c|}{ Effect Size } & \multicolumn{2}{|c|}{ Heterogeneity } \\
\hline & & & & & & & $\mathbf{Z}$ & P-value & P-value & $\mathbf{I}^{2}$ \\
\hline & High-quality & 2 & 121 & 2.37 & 1.37 & 4.09 & 3.08 & 0.002 & 0.51 & $0 \%$ \\
\hline & Disease stage & & & & & & & & & \\
\hline & Non-metastatic & 3 & 387 & 3.31 & 1.55 & 7.07 & 3.09 & 0.002 & 0.2 & $37 \%$ \\
\hline & Metastatic/mixed & 1 & 99 & 1.11 & 0.39 & 3.18 & 0.20 & 0.84 & - & - \\
\hline & HR & & & & & & & & & \\
\hline & Reported in study & 2 & 209 & 2.85 & 0.42 & 19.47 & 1.07 & 0.29 & 0.02 & $81 \%$ \\
\hline & $\begin{array}{l}\text { Estimated from } \\
\text { survival curves }\end{array}$ & 2 & 121 & 2.37 & 1.37 & 4.09 & 3.08 & 0.002 & 0.51 & $0 \%$ \\
\hline
\end{tabular}

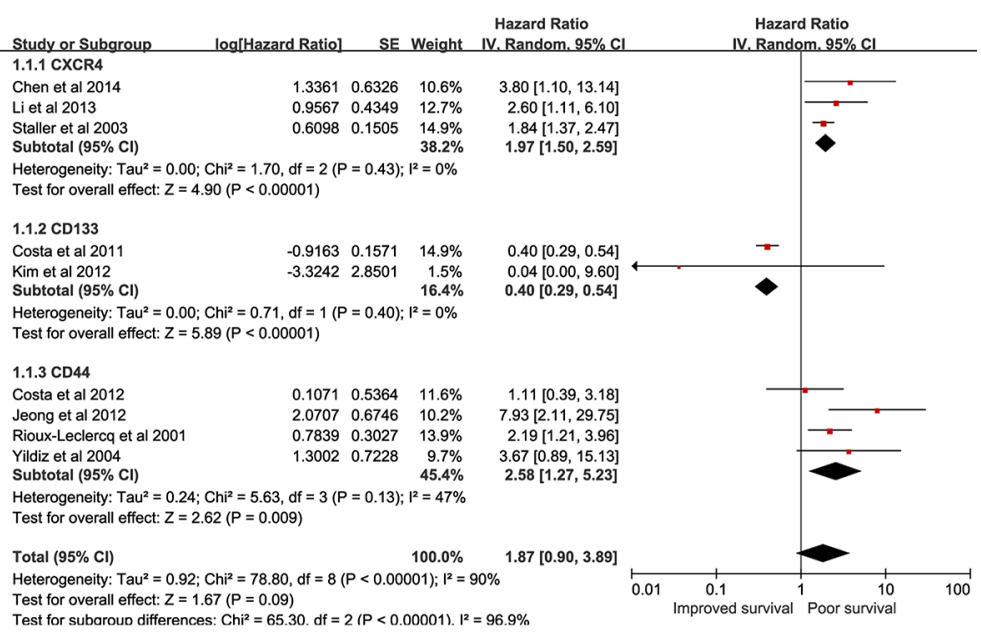

Figure 3: forest plot reflects HR with $95 \%$ CI for CSS.

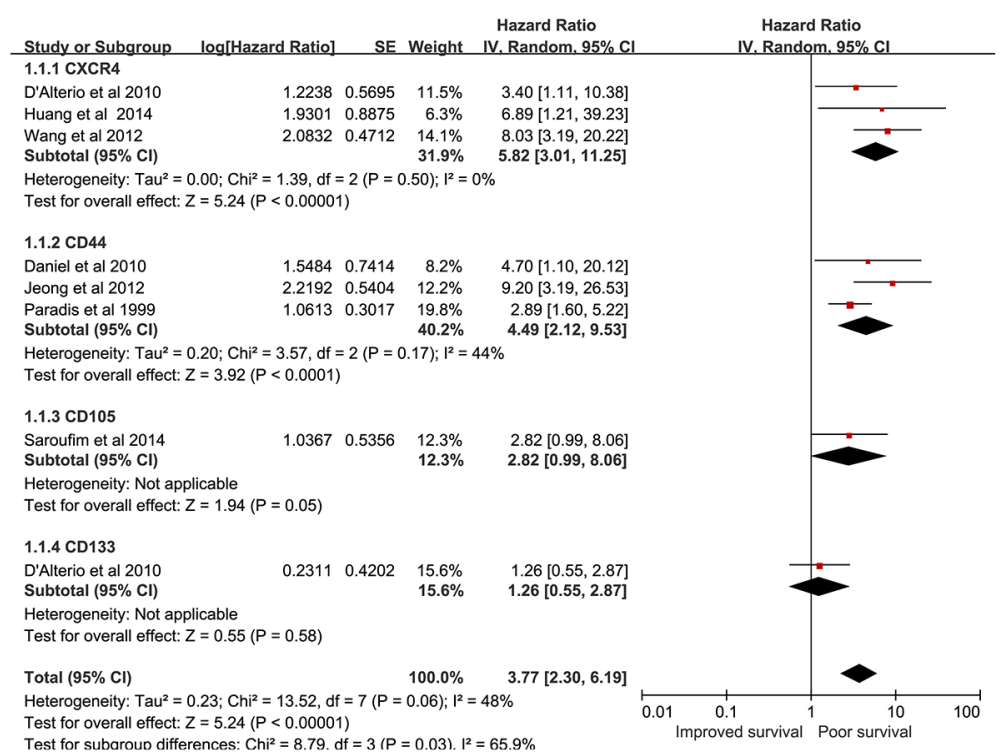

Figure 4: forest plot reflects HR with $95 \% \mathrm{CI}$ for DFS. 
Table 3: The influence of individual study on the pooled estimate for outcomes

\begin{tabular}{|c|c|c|c|c|c|c|}
\hline \multirow[t]{2}{*}{ Outcomes } & \multirow[t]{2}{*}{ Study omitted } & \multirow[t]{2}{*}{ Years } & \multirow[t]{2}{*}{ HR } & \multirow[t]{2}{*}{$95 \% \mathrm{CI}$} & \multicolumn{2}{|c|}{ Heterogeneity } \\
\hline & & & & & $I^{2}(\%)$ & $P$ value \\
\hline \multirow[t]{9}{*}{ OS(CXCR4) } & None & & 2.57 & $1.95-3.40$ & $42 \%$ & 0.10 \\
\hline & An et al (cohort 1 ) & 2014 & 2.48 & $1.85-3.34$ & $48 \%$ & 0.07 \\
\hline & An et al (cohort 2) & 2014 & 2.54 & $1.89-3.41$ & $50 \%$ & 0.06 \\
\hline & D'Alterio et al & 2012 & 3.43 & $2.43-4.83$ & $0 \%$ & 0.53 \\
\hline & Gassenmaier et al & 2012 & 2.51 & $1.88-3.34$ & $48 \%$ & 0.07 \\
\hline & Huang et al & 2014 & 2.52 & $1.90-3.34$ & $47 \%$ & 0.08 \\
\hline & Li et al & 2011 & 2.42 & $1.80-3.26$ & $44 \%$ & 0.10 \\
\hline & Li et al & 2013 & 2.65 & $1.96-3.60$ & $49 \%$ & 0.06 \\
\hline & Wang et al & 2012 & 2.38 & $1.78-3.17$ & $27 \%$ & 0.22 \\
\hline \multirow[t]{8}{*}{$\mathrm{OS}(\mathrm{CD} 44)$} & None & & 1.58 & $1.14-2.18$ & $23 \%$ & 0.25 \\
\hline & Bamias et al & 2003 & 1.77 & $1.24-2.53$ & $9 \%$ & 0.36 \\
\hline & Jeong et al & 2012 & 1.42 & $1.01-2.00$ & $0 \%$ & 0.51 \\
\hline & Lucin et al & 2004 & 1.50 & $1.07-2.09$ & $23 \%$ & 0.26 \\
\hline & Mikami et al & 2014 & 1.58 & $1.14-2.20$ & $36 \%$ & 0.17 \\
\hline & Qin et al & 2014 & 1.52 & $1.08-2.11$ & $29 \%$ & 0.22 \\
\hline & Tawfik et al & 2007 & 1.70 & $1.18-2.45$ & $30 \%$ & 0.21 \\
\hline & Zhang et al & 2013 & 1.64 & $1.11-2.41$ & $35 \%$ & 0.17 \\
\hline \multirow[t]{4}{*}{ CSS(CXCR4) } & None & & 1.97 & $1.50-2.59$ & $0 \%$ & 0.45 \\
\hline & Chen et al & 2014 & 1.91 & $1.44-2.52$ & $0 \%$ & 0.46 \\
\hline & Li et al & 2013 & 2.00 & $1.27-3.14$ & $14 \%$ & 0.28 \\
\hline & Staller et al & 2003 & 2.92 & $1.43-5.98$ & $0 \%$ & 0.63 \\
\hline \multirow[t]{5}{*}{$\mathrm{CSS}(\mathrm{CD} 44)$} & None & & 2.58 & $1.27-5.23$ & $47 \%$ & 0.13 \\
\hline & Costa et al & 2012 & 3.31 & $1.55-7.07$ & $37 \%$ & 0.20 \\
\hline & Jeong et al & 2012 & 2.01 & $1.24-3.27$ & $0 \%$ & 0.37 \\
\hline & Rioux-Leclercq et al & 2001 & 3.00 & $0.91-9.96$ & $63 \%$ & 0.07 \\
\hline & Yildiz et al & 2004 & 2.25 & $1.39-5.99$ & $62 \%$ & 0.07 \\
\hline \multirow[t]{4}{*}{ DFS(CXCR4) } & None & & 5.82 & $3.01-11.25$ & $0 \%$ & 0.50 \\
\hline & D'Alterio et al & 2010 & 7.76 & $3.43-17.55$ & $0 \%$ & 0.88 \\
\hline & Huang et al & 2014 & 5.55 & $2.41-12.77$ & $26 \%$ & 0.24 \\
\hline & Wang et al & 2012 & 4.18 & $1.63-10.69$ & $0 \%$ & 0.50 \\
\hline \multirow[t]{4}{*}{$\mathrm{DFS}(\mathrm{CD} 44)$} & None & & 4.49 & $2.12-9.53$ & $44 \%$ & 0.17 \\
\hline & Daniel et al & 2001 & 4.73 & $1.54-14.52$ & $71 \%$ & 0.06 \\
\hline & Jeong et al & 2012 & 3.10 & $1.79-5.36$ & $0 \%$ & 0.54 \\
\hline & Paradis et al & 1999 & 7.29 & $3.10-17.16$ & $0 \%$ & 0.46 \\
\hline
\end{tabular}

HR: Hazard ratio; CI: Confidence interval. 
will provide valuable therapeutic and prognostic targets for clinical practice. Recently, relevant markers of CSCs have been found to be independent prognostic factors for various cancers [47, 48]. While some studies have revealed that CSCs markers can be associated with RCC prognosis, others have not $[31,38,40]$. In our metaanalysis, we have attempted to resolve the conflicting data and thus to quantitatively estimate the prognostic value of CSCs markers in RCC patients.

This meta-analysis of 25 studies, including 2673 participants, indicated that adverse prognostic effects of CSCs markers on OS and DFS. The pooled data suggest that CSCs markers could be used as indicators of RCC outcome. A body of evidence indicates that CSCs can facilitate renal cancer cell growth, invasion and metastasis $[26,49]$, which may partially explain the association of CSCs markers expression with clinical outcome. In the stratified analysis by individual CSCs markers, combined HR showed that high expression of CXCR4 predicted poor prognosis of OS, especially in Asia, as well as CSS and DFS . One of reasonable explanation might be the stromal derived factor-1 (SDF-1/CXCR4) axis hypothesis. One study indicated that SDF-1, via interaction with CXCR4, contributed to RCC metastatic potential [50]. CD44, as a multifunctional cell surface adhesion molecule, has been identified as a marker of RCC CSCs. Another study found that an activated TNF-a/CD44 axis facilitates progression of RCC by enhancing epithelial-mesenchymal transition

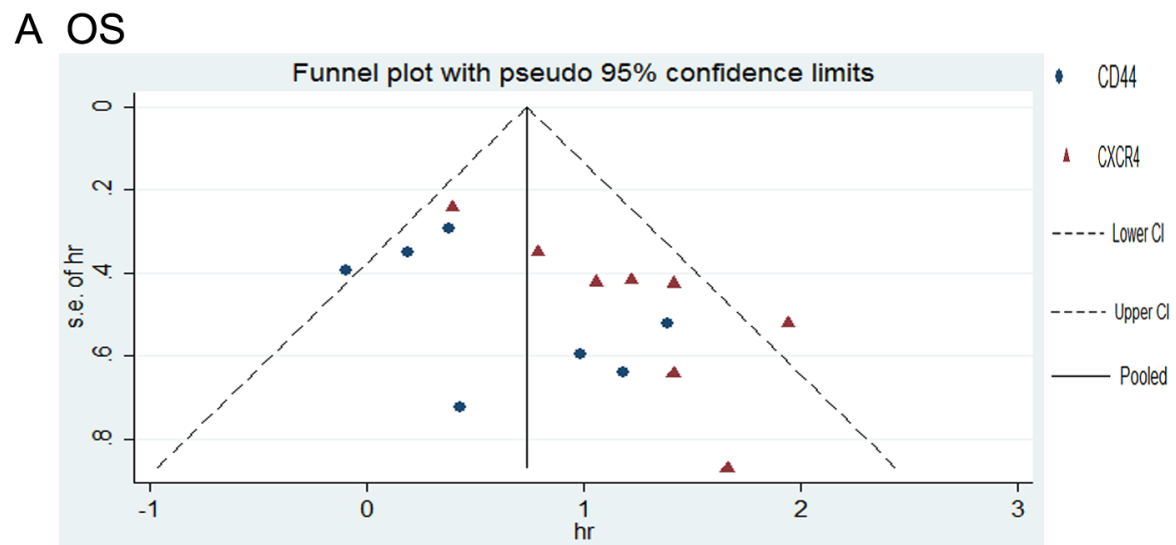

B CSS Funnel plot with pseudo $95 \%$ confidence limits

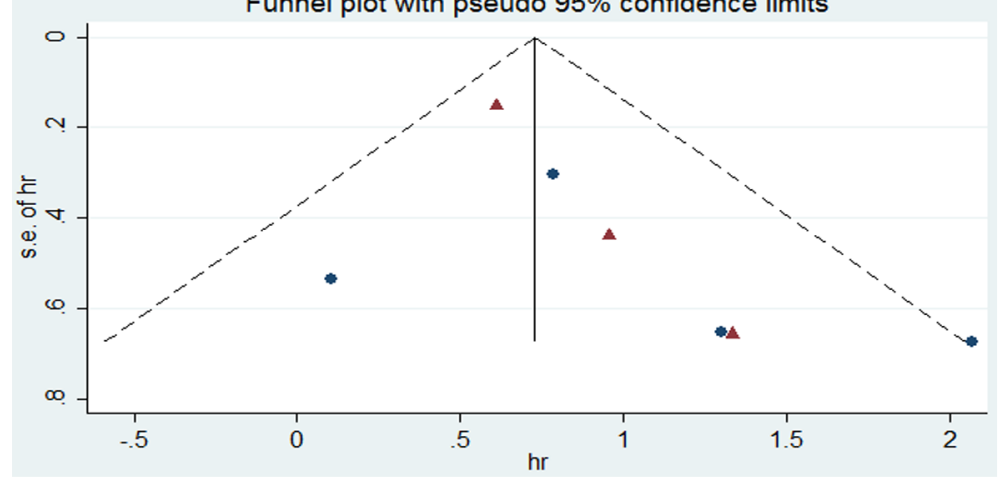

C DFS

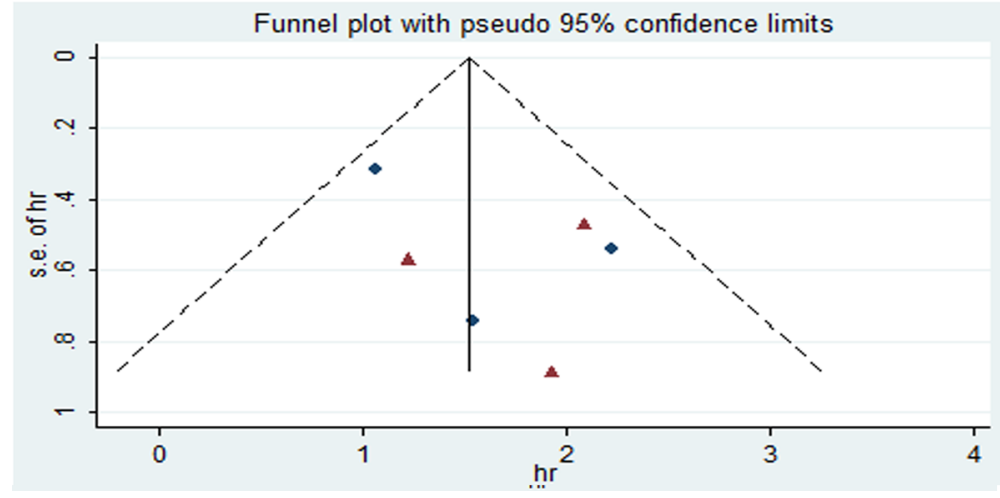

Figure 5: funnel plot for publication bias. 
Table 4: Publication bias was determined for outcomes by begg and egger tests

\begin{tabular}{|c|c|c|c|c|c|}
\hline \multirow[t]{2}{*}{ Outcomes } & \multirow[t]{2}{*}{ Marker } & \multicolumn{2}{|c|}{ Begg's test } & \multicolumn{2}{|c|}{ Egger's test } \\
\hline & & P value & t-value & $95 \% \mathrm{CI}$ & P value \\
\hline OS & CXCR4+CD44 & 0.09 & 2.75 & $0.51-4.27$ & 0.02 \\
\hline OS & CXCR4 & 0.03 & 3.95 & $1.17-4.97$ & 0.01 \\
\hline OS & CD44 & 0.55 & 1.65 & $-1.15-5.30$ & 0.16 \\
\hline CSS & CXCR4+CD44 & 0.07 & 1.75 & $-0.55-2.91$ & 0.14 \\
\hline CSS & CXCR4 & 0.30 & 10.75 & $-0.24-2.92$ & 0.06 \\
\hline $\mathrm{CSS}$ & $\mathrm{CD} 44$ & 0.31 & 0.68 & $-8.09-11.3$ & 0.57 \\
\hline DFS & CXCR4+CD44 & 0.71 & 1.25 & $-1.93-5.10$ & 0.28 \\
\hline DFS & CXCR4 & 1.00 & -0.16 & $-36.15-35.27$ & 0.90 \\
\hline DFS & CD44 & 1.00 & 1.00 & $-26.44-30.93$ & 0.50 \\
\hline
\end{tabular}

(EMT) [31]. Consistent with the previous report, our study suggests that high expression of CD44 significantly correlate with unfavorable OS, CSS and DFS. There are a few references about the relationship between CD133 and CD105 expression and RCC clinical outcome [14, $29,35,40]$. The pooled HR suggests CD133 to be an independent favorable prognostic factor for CSS. CD133 was one of the most commonly used CSCs markers, and numerous studies indicated CD133 over-expression in cancer patients exhibited a poor prognosis [51, 52] . Considering that the sample sizes are relatively limited, these results need to be cautiously interpreted. Currently, CSCs modulators have been moved from theoretical basic research into preclinical and early clinical trials. CXCR4 inhibitor AMD3100 facilitates anti-angiogenic agents sunitinib and sorafenib anticancer effects via blockade of CXCR4 $4^{+}$RCC CSCs [11]. Also, it has been reported that IL-15 treatment of RCC CD $105^{+} \mathrm{CSCs}$ could suppress cancer progression [10]. Since the association of CSCs markers with metastatic RCC survival (PFS) is scarce in literature, we did not reassess the correlation. Further investigation of the prognostic value of CSCs markers in metastatic RCC should be designed.

Several potential limitations should be acknowledged and some results need to be interpreted cautiously. The number of eligible studies was relatively small, especially in assessing the association of CD133 and $\mathrm{CD} 105$ with RCC prognosis, thus reducing the power of the results. The total sample sizes were relatively limited, which might lead to an erroneous conclusion. All of the enrolled studies were retrospective, making them more susceptible to information and selection biases. This study was constrained to articles published in English, which might contribute to selection bias. Moreover, for studies that did not provide HR and 95\% CI directly, we evaluated and calculated the HRs via survival curves. This method might reduce the credibility of the results. Additionally, publication bias existed for
OS, thus inflating the estimate for the association of CXCR4 with poor prognosis. The quality of included studies was assessed by NOS. We found heterogeneity may come from low-quality studies according to the results of subgroup analysis. Furthermore, the variations of the characteristics of patients and the various detecting antibodies against CSCs markers might have caused inherent heterogeneity within studies.

In conclusion, despite certain limitations, the present results provide some evidence on the prognostic value of CSCs markers in RCC. The presence of CSCs is associated with a poor clinical outcome. High CXCR4 and CD44 expression predicts a worse OS CSS and DFS. CD133 is an independent favorable prognostic factor for CSS. CSCs markers may potentially serve as prognostic stratification markers and novel potential therapeutic targets for RCC. Further large-scale and standard cohort studies are required for confirmation.

\section{MATERIALS AND METHODS}

\section{Literature search strategy}

This study adhered to the PRISMA guidelines [53]. A comprehensive literature search was conducted using PubMed and EMBASE databases from inception to 1 February 2016 in order to identify published articles assessing the prognostic value of CSCs markers in RCC. The terms for synonyms: "renal or kidney," "cancer or tumor or carcinoma," "CD44," "Endoglin or CD105," "Prominin-1 or CD133," "CXCR4," "prognosis or survival or outcome," were applied during the search. Searches were limited to publications in English. The PubMed and EMBASE databases search options were summarized in "Appendix". The bibliographies of articles were also checked for additional eligible studies. Results and any disagreements were double-checked and arbitrated by a second reviewer. 


\section{Study selection}

All candidate articles initially were screened by titles and/or abstracts using the following inclusion criteria: 1) patients with RCC diagnosis which were pathologically confirmed; 2) RCC CSCs relevant markers (CD133, CXCR4, CD44, and CD105) expression was examined by immunohistochemistry (IHC) or polymerase chain reaction (PCR); 3) studies evaluated the association of CSCs markers expression with RCC survival outcomes [(disease-free survival (DFS), overall survival (OS), cancer-specific survival (CSS), progression-free survival (PFS)], hazard ratios (HR) with $95 \%$ confidence intervals (CI); 4) sample size $\geq 20$ cases; 5) If multiple articles were reported by the same cohorts, only the most complete paper was included. Non-research articles or studies that were focused on animal or human cell lines or papers lacking information on RCC prognosis were excluded.

\section{Data extraction}

All eligible studies were identified by two independent investigators. The following data were extracted: general information (first author's surname, year of publication, country of origin), study population characteristics (patients number, age, and sex), follow-up data (median/mean follow-up duration, OS, CSS, PFS, and DFS with corresponding 95\% CI), CSCs markers expression data (assessment method and cut-off value). If the HR and 95\% CI were not displayed directly, they were estimated from Kaplan-Meier curves as reported by Tierney et al [54].

\section{Qualitative assessment}

The quality of each of the eligible studies was assessed independently by 2 investigators using the Newcastle-Ottawa Quality Assessment Scale (NOS) for cohort studies (Supplemental Table S2). Briefly, the scale uses a star system to indicate the quality of each study (Supplemental Table S3). Studies that received a score of $\geq 7$ stars were considered to be of high quality [55].

\section{Statistical analysis}

HR values with $95 \% \mathrm{CI}$ for OS, CSS, PFS, and DFS according to the expression of CSCs markers were pooled. In this study, a combined HR $>1$ reflected a worse prognosis for high CSCs markers expression patents, while a pooled $\mathrm{HR}<1$ indicated a better survival. $\mathrm{Z}$ test for pooled $\mathrm{HR}$ and a P-value $<0.05$, or no overlap of the $95 \%$ CI with 1 was considered statistically significant. The fixed-effects model (FEM) or the random-effects model (REM) was used to evaluate heterogeneity [56], which was verified using chi-square-based Cochran Q-test. The $\mathrm{I}^{2}$ value implied the degree of heterogeneity. The REM was used for data showing statistically significant heterogeneity if $\mathrm{P}<0.05$ and/or $\mathrm{I}^{2}>50 \%$, otherwise, FEM was applied. Subgroup analysis was performed to explore the potential sources of heterogeneity. Potential publication bias was assessed by funnel plot and precisely evaluated by Egger's and Begg's tests [57, 58] . The robustness of the pooled data was examined by sensitivity analysis. Kaplan-Meier curves were read by Engauge Digitizer version 4.1(http://sourceforge.net). Stata 10.0 (Stata Corporation, College Station, TX, USA) and Review Manager 5.2 (Cochrane Collaboration, London, UK) were used to statistical analyses in this study. All statistical tests were two-sided.

\section{CONFLICTS OF INTEREST}

The authors proclaim that they have no conflict of interest in this study.

\section{REFERENCES}

1. Jonasch E, Gao J and Rathmell WK. Renal cell carcinoma. BMJ (Clinical research ed). 2014; 349:g4797.

2. Siegel RL, Miller KD and Jemal A. Cancer statistics, 2016. CA: a cancer journal for clinicians. 2016; 66:7-30.

3. Lee-Ying R, Lester R and Heng D. Current management and future perspectives of metastatic renal cell carcinoma. International journal of urology. 2014; 21:847-855.

4. Motzer RJ, Jonasch E, Agarwal N, Beard C, Bhayani S, Bolger GB, Chang SS, Choueiri TK, Costello BA, Derweesh IH, Gupta S, Hancock SL, Kim JJ, et al. Kidney cancer, version 3.2015. Journal of the National Comprehensive Cancer Network. 2015; 13:151-159.

5. Abe H and Kamai T. Recent advances in the treatment of metastatic renal cell carcinoma. International journal of urology. 2013; 20:944-955.

6. Nguyen KS, Kobayashi S and Costa DB. Acquired resistance to epidermal growth factor receptor tyrosine kinase inhibitors in non-small-cell lung cancers dependent on the epidermal growth factor receptor pathway. Clinical lung cancer. 2009; 10:281-289.

7. Ljungberg B, Cowan NC, Hanbury DC, Hora M, Kuczyk MA, Merseburger AS, Patard JJ, Mulders PF and Sinescu IC. EAU guidelines on renal cell carcinoma: the 2010 update. European urology. 2010; 58:398-406.

8. Gulati S, Martinez P, Joshi T, Birkbak NJ, Santos CR, Rowan AJ, Pickering L, Gore M, Larkin J, Szallasi Z, Bates PA, Swanton C and Gerlinger M. Systematic evaluation of the prognostic impact and intratumour heterogeneity of clear cell renal cell carcinoma biomarkers. European urology. 2014; 66:936-948. 
9. Zimpfer A, Maruschke M, Rehn S, Kundt G, Litzenberger A, Dammert F, Zettl H, Stephan C, Hakenberg OW and Erbersdobler A. Prognostic and diagnostic implications of epithelial cell adhesion/activating molecule (EpCAM) expression in renal tumours: a retrospective clinicopathological study of 948 cases using tissue microarrays. BJU international. 2014; 114:296-302.

10. Azzi S, Bruno S, Giron-Michel J, Clay D, Devocelle A, Croce M, Ferrini S, Chouaib S, Vazquez A, Charpentier B, Camussi G, Azzarone B and Eid P. Differentiation therapy: targeting human renal cancer stem cells with interleukin 15. J Natl Cancer Inst. 2011; 103:1884-1898.

11. Myszczyszyn A, Czarnecka AM, Matak D, Szymanski L, Lian F, Kornakiewicz A, Bartnik E, Kukwa W, Kieda C and Szczylik C. The Role of Hypoxia and Cancer Stem Cells in Renal Cell Carcinoma Pathogenesis. Stem cell reviews. 2015; 11:919-943.

12. Cho YM. High-level expression of stem cell marker CD133 in clear cell renal cell carcinoma with favorable prognosis. Oncology Letters. 2011; 2:1095-1100.

13. Matak D, Szymanski L, Szczylik C, Sledziewski R, Lian F, Bartnik E, Sobocinska A and Czarnecka AM. Biology of renal tumour cancer stem cells applied in medicine. Contemp Oncol (Pozn). 2015; 19(1a):A44-51.

14. D'Alterio C, Cindolo L, Portella L, Polimeno M, Consales C, Riccio A, Cioffi M, Franco R, Chiodini P, Cartenì G, Mirone V, Longo N, Marra L, et al. Differential role of CD133 and CXCR4 in renal cell carcinoma. Cell Cycle. 2010; 9:4492-4500.

15. Staller P, Sulitkova J, Lisztwan J, Moch H, Oakeley EJ and Krek W. Chemokine receptor CXCR4 downregulated by von Hippel-Lindau tumour suppressor pVHL. Nature. 2003; 425:307-311.

16. D'Alterio C, Consales C, Polimeno M, Franco R, Cindolo L, Portella L, Cioffi M, Calemma R, Marra L, Claudio L, Perdona S, Pignata S, Facchini G, et al. Concomitant CXCR4 and CXCR7 expression predicts poor prognosis in renal cancer. Current cancer drug targets. 2010; 10:772-781.

17. Lucin K, Matusan K, Dordevic G and Stipic D. Prognostic significance of CD44 molecule in renal cell carcinoma. Croat Med J. 2004; 45:703-708.

18. Bamias A, Chorti M, Deliveliotis C, Trakas N, Skolarikos A, Protogerou B, Legaki S, Tsakalou G, Tamvakis N and Dimopoulos MA. Prognostic significance of CA 125, CD44, and epithelial membrane antigen in renal cell carcinoma. Urology. 2003; 62:368-373.

19. Tawfik OW, Kramer B, Shideler B, Danley M, Kimler BF and Holzbeierlein J. Prognostic significance of CD44, plateletderived growth factor receptor $\alpha$, and cyclooxygenase 2 expression in renal cell carcinoma. Archives of Pathology and Laboratory Medicine. 2007; 131:261-267.

20. Sandlund J, Hedberg Y, Bergh A, Grankvist K, Ljungberg $\mathrm{B}$ and Rasmuson T. Endoglin (CD105) expression in human renal cell carcinoma. BJU international. 2006; 97:706-710.

21. Saroufim A, Messai Y, Hasmim M, Rioux N, Iacovelli R, Verhoest G, Bensalah K, Patard JJ, Albiges L, Azzarone B, Escudier B and Chouaib S. Tumoral CD105 is a novel independent prognostic marker for prognosis in clear-cell renal cell carcinoma. British Journal of Cancer. 2014; 110:1778-1784.

22. An H, Xu L, Zhu Y, Lv T, Liu W, Liu Y, Liu H, Chen L, Xu J and Lin Z. High CXC chemokine receptor 4 expression is an adverse prognostic factor in patients with clear-cell renal cell carcinoma. British Journal of Cancer. 2014; 110:2261-2268.

23. Chen D, Gassenmaier M, Maruschke M, Riesenberg R, Pohla H, Stief CG, Zimmermann W and Buchner A. Expression and prognostic significance of a comprehensive epithelial-mesenchymal transition gene set in renal cell carcinoma. Journal of Urology. 2014; 191:479-486.

24. D'Alterio C, Portella L, Ottaiano A, Rizzo M, Cartenì G, Pignata S, Facchini G, Perdonà S, Di Lorenzo G, Autorino R, Franco R, la Mura A, Nappi O, Castello G and Scala S. High CXCR4 expression correlates with sunitinib poor response in metastatic renal cancer. Current Cancer Drug Targets. 2012; 12:693-702.

25. Daniel L, Lechevallier E, Giorgi R, Lindner V, De Fromont M, Vieillefond A, Coulange C and Figarella-Branger D. CD44s and CD44v6 expression in localized T1-T2 conventional renal cell carcinomas. Journal of Pathology. 2001; 193:345-349.

26. Gassenmaier M, Chen D, Buchner A, Henkel L, Schiemann M, Mack B, Schendel DJ, Zimmermann W and Pohla H. CXC chemokine receptor 4 is essential for maintenance of renal cell carcinoma-initiating cells and predicts metastasis. Stem Cells. 2013; 31:1467-1476.

27. Huang CS, Tang SJ, Chung LY, Yu CP, Ho JY, Cha TL, Hsieh CC, Wang HH, Sun GH and Sun KH. Galectin-1 upregulates CXCR4 to promote tumor progression and poor outcome in kidney cancer. Journal of the American Society of Nephrology. 2014; 25:1486-1495.

28. Jeong BJ, Liang ZL, Huang SM, Lim JS, Kim JM and Lee HJ. CD44 is associated with tumor recurrence and is an independent poor prognostic factor for patients with localized clear cell renal cell carcinoma after nephrectomy. Experimental and Therapeutic Medicine. 2012; 3:811-817.

29. Kim K, Ro JY, Kim S and Cho YM. Expression of stem-cell markers OCT-4 and CD133: Important prognostic factors in papillary renal cell carcinoma. Human Pathology. 2012; 43:2109-2116.

30. Li X, Huang Y, Xia J, Chen N, Wei Q, Li X, Zhang P, Shen $\mathrm{PF}$, Wang $\mathrm{J}$ and Zeng $\mathrm{H}$. CXCR4 expression in patients with high-risk locally advanced renal cell carcinoma can independently predict increased risk of disease progression and poor overall survival. Asian Pacific journal of cancer prevention. 2011; 12:3313-3318.

31. Mikami S, Mizuno R, Kosaka T, Saya H, Oya M and Okada Y. Expression of TNF- $\alpha$ and CD44 is implicated in poor 
prognosis, cancer cell invasion, metastasis and resistance to the sunitinib treatment in clear cell renal cell carcinomas. International Journal of Cancer. 2015; 136:1504-1514.

32. Paradis V, Ferlicot S, Ghannam E, Zeimoura L, Blanchet P, Eschwége P, Jardin A, Benoît G and Bedossa P. CD44 is an independent prognostic factor in conventional renal cell carcinomas. Journal of Urology. 1999; 161:1984-1987.

33. Qin J, Yang B, Xu BQ, Smithc A, Xu L, Yuan JL and Li L. Concurrent CD44s and STAT3 expression in human clear cell renal cellular carcinoma and its impact on survival. International journal of clinical and experimental pathology. 2014; 7:3235-3244.

34. Rioux-Leclercq N, Epstein JI, Bansard JY, Turlin B, Patard JJ, Manunta A, Chan T, Ramee MP, Lobel B and Moulinoux JP. Clinical significance of cell proliferation, microvessel density, and CD44 adhesion molecule expression in renal cell carcinoma. Human Pathology. 2001; 32:1209-1215.

35. Saroufim A, Messai Y, Hasmim M, Rioux N, Iacovelli R, Verhoest G, Bensalah K, Patard JJ, Albiges L, Azzarone B, Escudier B and Chouaib S. Tumoral CD105 is a novel independent prognostic marker for prognosis in clear-cell renal cell carcinoma. Br J Cancer. 2014; 110:1778-1784.

36. Wang L, Chen W, Gao L, Yang Q, Liu B, Wu Z, Wang $\mathrm{Y}$ and Sun Y. High expression of CXCR4, CXCR7 and SDF-1 predicts poor survival in renal cell carcinoma. World Journal of Surgical Oncology. 2012; 10:212.

37. Yildiz E, Gokce G, Kilicarslan H, Ayan S, Goze OF and Gultekin EY. Prognostic value of the expression of Ki-67, CD44 and vascular endothelial growth factor, and microvessel invasion, in renal cell carcinoma. BJU international. 2004; 93:1087-1093.

38. Zhang Y, Sun B, Zhao X, Liu Z, Wang X, Yao X, Dong X and Chi J. Clinical significances and prognostic value of cancer stem-like cells markers and vasculogenic mimicry in renal cell carcinoma. Journal of Surgical Oncology. 2013; 108:414-419.

39. Costa WH, Rocha RM, Cunha IW, Guimaraes GC and Zequi Sde C. Immunohistochemical expression of CD44s in renal cell carcinoma lacks independent prognostic significance. Int Braz J Urol. 2012; 38:456-465.

40. Costa WH, Rocha RM, Cunha IW, Fonseca FP, Guimaraes GC and Zequi Sde C. CD133 immunohistochemical expression predicts progression and cancer-related death in renal cell carcinoma. World J Urol. 2012; 30:553-558.

41. Li G, Badin G, Zhao A, Gentil-Perret A, Tostain J, Péoc'h $\mathrm{M}$ and Gigante M. Prognostic value of CXCR4 expression in patients with clear cell renal cell carcinoma. Histology and histopathology. 2013; 28:1217-1222.

42. Ingels $\mathrm{A}$, Zhao $\mathrm{H}$, Thong $\mathrm{AE}$, Saar M, Valta MP, Nolley R, Santos J and Peehl DM. Preclinical trial of a new dual mTOR inhibitor, MLN0128, using renal cell carcinoma tumorgrafts. Int J Cancer. 2014; 134:2322-2329.

43. Bitting RL, Healy P, Creel PA, Turnbull J, Morris K, Wood SY, Hurwitz HI, Starr MD, Nixon AB, Armstrong AJ and
George DJ. A phase Ib study of combined VEGFR and mTOR inhibition with vatalanib and everolimus in patients with advanced renal cell carcinoma. Clinical genitourinary cancer. $2014 ; 12: 241-250$.

44. Meacham CE and Morrison SJ. Tumour heterogeneity and cancer cell plasticity. Nature. 2013; 501:328-337.

45. Liao S-K, Ting L-L, Chou A-B, Hsieh C-H, Hsiung S-C and Pang S-T. Withaferin A targeting both cancer stem cells and metastatic cancer stem cells in the UP-LN1 carcinoma cell model. Journal of Cancer Metastasis and Treatment. 2015; $0: 0$.

46. Schulenburg A, Blatt K, Cerny-Reiterer S, Sadovnik I, Herrmann H, Marian B, Grunt TW, Zielinski CC and Valent P. Cancer stem cells in basic science and in translational oncology: can we translate into clinical application? Journal of hematology \& oncology. 2015; 8:16.

47. Zhang X, Hua R, Wang X, Huang M, Gan L, Wu Z, Zhang J, Wang H, Cheng Y, Li J and Guo W. Identification of stemlike cells and clinical significance of candidate stem cell markers in gastric cancer. Oncotarget. 2016; 7:9815-9831. doi: 10.18632/oncotarget.6890.

48. Kim N, Choung HK, Lee MJ, Khwarg SI and Kim JE. Cancer Stem Cell Markers in Eyelid Sebaceous Gland Carcinoma: High Expression of ALDH1, CD133, and ABCG2 Correlates With Poor Prognosis. Investigative ophthalmology \& visual science. 2015; 56:1813-1819.

49. Lucarelli G, Galleggiante V, Rutigliano M, Vavallo A, Ditonno P and Battaglia M. Isolation and characterization of cancer stem cells in renal cell carcinoma. Urologia. 2015; 82:46-53.

50. Pan J, Mestas J, Burdick MD, Phillips RJ, Thomas GV, Reckamp K, Belperio JA and Strieter RM. Stromal derived factor-1 (SDF-1/CXCL12) and CXCR4 in renal cell carcinoma metastasis. Molecular cancer. 2006; 5:56.

51. Yiming L, Yunshan G, Bo M, Yu Z, Tao W, Gengfang L, Dexian F, Shiqian C, Jianli J, Juan T and Zhinan C. CD133 overexpression correlates with clinicopathological features of gastric cancer patients and its impact on survival: a systematic review and meta-analysis. Oncotarget. 2015; 6:42019-42027. doi: 10.18632/oncotarget.5714.

52. Zhou Q, Chen A, Song H, Tao J, Yang H and Zuo M. Prognostic value of cancer stem cell marker CD133 in ovarian cancer: a meta-analysis. International journal of clinical and experimental medicine. 2015; 8:3080-3088.

53. Moher D, Liberati A, Tetzlaff J and Altman DG. Preferred reporting items for systematic reviews and meta-analyses: the PRISMA Statement. Open medicine. 2009; 3:e123-130.

54. Tierney JF, Stewart LA, Ghersi D, Burdett S and Sydes MR. Practical methods for incorporating summary time-to-event data into meta-analysis. Trials. 2007; 8:16.

55. Wong WC, Cheung CS and Hart GJ. Development of a quality assessment tool for systematic reviews of observational studies (QATSO) of HIV prevalence in 
men having sex with men and associated risk behaviours. Emerging themes in epidemiology. 2008; 5:23.

56. Wu T, Jiao M, Jing L, Wang MC, Sun HF, Li Q, Bai YY, Wei YC, Nan KJ and Guo H. Prognostic value of Notch-1 expression in hepatocellular carcinoma: a meta-analysis. OncoTargets and therapy. 2015; 8:3105-3114.
57. Begg CB and Mazumdar M. Operating characteristics of a rank correlation test for publication bias. Biometrics. 1994; 50:1088-1101.

58. Song F and Gilbody S. Bias in meta-analysis detected by a simple, graphical test. Increase in studies of publication bias coincided with increasing use of meta-analysis. BMJ (Clinical research ed). 1998; 316:471. 